\title{
\#Black Lives Matter? Analyzing the Effects of Police-Caused Black Deaths on Media Coverage and Public Interest in the Movement
}

\section{Francesca Bordonaro and Dale Willits I}

\begin{abstract}
Black Lives Matter is a social movement, created and maintained on social media networks; its formation was spurred in part by the number of Black men and women who have been killed by police officers in the United States. This research focuses on the relationship between police-caused deaths of Black men and women and media coverage of and public interest in Black Lives Matter. The primary goal of the research was to determine whether traditional news coverage of Black Lives Matter was linked to the killings of Black citizens by police. We found that Black citizen deaths did not result in increased mentions of Black Lives Matter in either newspaper articles or Google searches. We did, however, find that when police officers were killed at a protest, mentions of Black Lives Matter in both the news and Google queries increased at a substantial rate, as did searches for "Blue Lives Matter." The implications for police use of force, Black Lives Matter, and traditional news media are discussed.
\end{abstract}

\section{Keywords}

Black Lives Matter, racial disparity, police use of force, media coverage

In February 2012, George Zimmerman shot and killed Trayvon Martin, a 17-year-old Black male, in Sanford, Florida (Freelon, Mcllwain, \& Clark, 2016). Following the 2013 acquittal of Zimmerman, the hashtag \#BlackLivesMatter was created by Alicia Garza, Patrisse

\footnotetext{
' Department of Criminal Justice \& Criminology, Washington State University, Pullman, Washington, USA

Corresponding Author:

Dale Willits, Department of Criminal Justice \& Criminology, Washington State University, Pullman, Washington, 99164, USA

E-mail: dale.willits@wsu.edu

The authors wish to express their appreciation to the blind reviewers of the original manuscript for their comments, which were helpful during preparation of the final version of the manuscript. The authors thank Davis Makin, Kim Andersen, and Duane Stanton for their helpful feedback on early drafts of this article.
} 
Cullors, and Opal Tometi (BlackLivesMatter, 2017), although the hashtag did not begin trending on Twitter until August 2014 (Freelon et al., 2016). Responding to the acquittal of Zimmerman, Garza, a community activist in Oakland, California, wrote the following message on Facebook: "Black people. I love you. I love us. Our lives matter." Cullors, a friend of Garza, then posted this statement: "Declaration: black bodies will no longer be sacrificed for the rest of the world's enlightenment. I am done. I am so done. Trayvon, you are loved infinitely. \#blacklivesmatter" (Cullors, 2017). This was the first use of the hashtag, which turned into a method of communicating the messages of the movement that is used worldwide, as well as a method for showing support. The hashtag spread across Twitter, Facebook, and Instagram when Ferguson police officer Darren Wilson shot and killed Michael Brown, whose body was left on the street for hours; this incident resulted in significant unrest (Buchanan et al., 2015). In essence, this hashtag spurred the formation of a social movement focusing largely on police officers' treatment of people of color (BlackLivesMatter, 2017).

Yet the portrayal of the \#BlackLivesMatter movement in the media has often been contentious. The protests and riots associated with the movement gained considerable national attention, and some commentators described the movement as "directionless" and "run by thugs" (French, 2016; Reynolds, 2015). Despite the fact that the Black Lives Matter movement has been associated with a number of policy successes, it is unclear that it has ever gained much traction from mainstream media sources, and it remains an online movement. Indeed, research demonstrates that Black Lives Matter has largely been maintained online through Twitter and other social media platforms (Ince, Rojas, \& Davis, 2017).

Although the prominent deaths of Black men, like Trayvon Martin and Michael Brown, have frequently been the catalyst for increased action on the part of the movement, resulting in protests, marches, and other highly visible activities, it is unclear that these have led to substantial mainstream media coverage or public interest in Black Lives Matter. This gap in knowledge is important because prior research has highlighted the role of media coverage in the success or failure of other movements (Bond, 2001; Hall, 2005). Moreover, we argue that interest in the movement is at least partially reflective of the level of interest in police-caused violence directed toward Black men and women, and although the amount of academic interest in this topic is substantial, it is not clear that the broader public is similarly concerned.

Although Black Lives Matter focuses on a number of outcomes, this loosely knit organization has frequently been organized and mobilized to combat racially biased policing. In this study, we examine general trends in traditional news media coverage of Black Lives Matter and the extent to which police-caused deaths of Black individuals are related to news and general public interest in Black Lives Matter. This research is important for two reasons: it documents trends and patterns in the Black Lives Matter movement, and it demonstrates the degree to which coverage of the movement corresponds to policecaused deaths of Black men and women. Indeed, one of the major contributions of the study is that it demonstrates that police violence against Black citizens generates very little news and public interest, and thereby demonstrates the very real need for the movement itself, inasmuch as there is little evidence to indicate that Black lives do in fact matter to the general public. 


\section{Black Lives Matter}

Black Lives Matter is organized as a "call to action in response to state-sanctioned violence and anti-Black racism" (Black Lives Matter, 2017), and as such, it attempts to engage directly the issue of differential policing previously described. To date, the organization has achieved several successes, including the launch of Campaign Zero, a comprehensive list of proposals to combat police violence, racial profiling, and misconduct through legislation and protest (WeTheProtesters, 2018). In addition, the movement has successfully secured meetings with politicians and police leaders to voice its concerns.

Despite recent debate regarding the degree to which police interactions with Black citizens are biased regarding the use of force (Rousell, Henne, Glover, \& Willits, 2017; Cesario, Johnson, \& Terrill, 2018), most of the literature indicates that Black communities and individuals are disproportionately policed, with outcomes often worse than those of Whites at the hands of the police. For example, evidence shows that police deployments are directed toward Black neighborhoods at disproportionate rates (Beckett, Nyrop, \& Pfingst, 2006), that Black people are searched at disproportionate rates (Gelman, Fagan, \& Kiss, 2007), that Black drivers are disproportionately pulled over for traffic stops (Lundman \& Kaufman, 2003), and that Black citizens are more likely than Whites to be arrested (Huizinga et al., 2007).

Black Lives Matter is an online-spurred movement that attempts to draw attention to the historical devaluation of Black men and women in the United States. Some debate is ongoing regarding the extent to which Black Lives Matter constitutes a social movement, given its loosely knit nature. The classic definition of a social network set forth by Diani (1992) requires that a social movement organization involve political or culturally informed and sustained interactions by individuals on the basis of a shared, collective identity. Black Lives Matter seems to meet this basic threshold, although the interactions therein typically occur online, and it is not completely clear to what extent the individuals who use the Black Lives Matter hashtag consistently have a shared, collective identity or the same goals. Mundt, Ross, and Burnett (2018) view Black Lives Matter's use of social media as an asset and in fact argue that its use of social media can serve as an organizing model for other social movements. Similarly, Byrd, Gilbert, and Richardson Jr. (2017) and Cox (2017) argue that the emphasis on social media as a communication and organizing framework makes Black Lives Matter different from past social movements, although importantly, a similar emphasis on organizing through social media was seen in the Occupy Movement (Kavada, 2015) and Arab Spring (Kamel, 2014). In summary, a small body of research seems to accept Black Lives Matter as a social movement, although one that is substantively different from older social movements.

Some of the successes of Black Lives Matter are evidenced by the creation of new hashtags and movements driven by social media. The hashtag \#iftheygunnedmedown was used to point out discrepancies in the headlines and photographs used by news agencies when reporting the deaths of persons killed by police. Most notably, headlines for stories about young White men who had committed crimes were compared with headlines for stories about young Black men who had been killed by police. The professionally taken photos of the White men were obtained from yearbooks or family photo shoots, and the headlines referred to them as suspects and mentioned their talents or bright futures. Alternatively, the Black men were shown in candid or nonstaged photographs, or with hand 
signs. The headlines described them as thugs and often blamed their deaths on actions they had taken before they were shot (Stampler, 2014). The examples given through this hashtag can reveal the discrepancies between White and Black America's interactions with police and media, just as Black Lives Matter works to illuminate those same discrepancies.

Broadly, however, it is unclear to what extent the Black Lives Matter movement has been successful in achieving its goals. Previous social movements with a racial orientation, like the Civil Rights Movement, have been linked to major federal initiatives, including the Civil Rights Act of 1964. Research also shows that the Civil Rights Movement has had a sustained effect on political outcomes over time, just as localized movements have continued to be successful in increasing Black political voices (Andrews, 1997). During its active years, the Civil Rights Movement was able to exert its influence as a social movement to generate news coverage (Andrews \& Biggs, 2006). It is unclear to what extent the same can be said of Black Lives Matter, although undoubtedly racially oriented social movements can be incredibly powerful.

Broad research has been undertaken on the devaluation of Black lives and the prevalence of stereotypical views about Black people. Sociological research demonstrates, for example, that perceptions of neighborhood safety are linked to Black population levels, even after control of neighborhood crime rates (Quillian \& Pager, 2001). Similarly, Hawkins (2002) directly argues that the historical devaluation of Black lives has resulted in a climate in which less attention is given to family violence in Black households. More broadly, a considerable amount of literature shows that Blacks are viewed as negative stereotypes by a substantial portion of the population (Greenwald, Poehlman, UhImann, \& Banaji, 2009; Sellers \& Shelton, 2003; Welch, 2007). Unsurprising, then, is the long history of unfavorable coverage in the media for people of color. Van Dijk (2015) has argued that contemporary news routines are based on perceptions of what is most likely to be of interest to White readers, and that these routines can serve to reproduce systemic racial biases. For example, reporters are more likely to use the term "riot" than "protest" in civil unrest events occurring in or around Black communities, which in turn may affect how news consumers view these communities. Evidence also indicates that coverage of Black individuals in natural disasters (Sommers, Apfelbaum, Dukes, Toosi, \& Wang, 2006) and in sports (Davis \& Harris, 2002) often invokes stereotypes. Regarding criminality, Oliver (2003) argues that the media's portrayal of race and crime represents the vital role that news plays in stereotyping people of color as violent and dangerous. Oliver (2003) found that news sources depict Black suspects as more dangerous than White suspects, overrepresenting them as perpetrators but underrepresenting them as victims. The subsequent effects can be seen in the attitudes and beliefs of news viewers. Those who view television news regularly are more likely to have racist views of people of color; they are more likely to believe that Black men are dangerous and more likely to suggest punitive measures (Oliver, 2003). Moreover, Chiricos and Eschholz (2002) show that television news coverage tends to portray Black (and Hispanic) crime suspects in more threatening contexts than Whites (who appear more frequently as victims in crime stories). Put simply, evidence indicates that media depictions of race and crime exaggerate stereotypes and reproduce racial biases (Van Dijk, 2015)

Yet, the coverage of race-based social movements is of great importance. Discussing the Civil Rights Movement, Hall (2005, p. 1236) notes that the media "made the protests 
one of the great news stories of the modern era." Although it would be simplistic to state that the successes associated with the Civil Rights Movement were possible only with media coverage, the media have historically played a key role in resource mobilization for social movements (Andrews \& Biggs, 2006). Regarding the Civil Rights Movement, Bond (2001) notes that media coverage can largely be divided into the "early era of factual reportage" and the later "period of increased suspicion, hostility, and cynicism," and that these eras can be linked to some extent to the successes and failures of the movement.

To date, very little research has examined mainstream or traditional news coverage of the Black Lives Matter movement, nor has the link between police-caused deaths of Black individuals (one of the primary topics discussed by the movement) and coverage of and interest in the movement been examined. Leopold and Bell (2017) provide perhaps the only direct examination of traditional news coverage for Black Lives Matter in their qualitative analysis of news articles following the death of Michael Brown. Like the authors of much of the prior literature, they found that most coverage included language that indicated disapproval of the protests and dissent and included strong elements of blame attribution toward Black victims. To date, no research has examined Black Lives Matter in a broad, quantitative sense, nor has any research examined general public interest in the movement.

The current study begins to address the gap in the literature by examining trends in the coverage of and public interest in the Black Lives Matter movement, and whether these trends have changed as a result of Black deaths. Given the broad arguments of Van Dijk (2015) regarding news coverage and social reproduction, and the history of unfavorable coverage applied to people of color, we hypothesize that Black deaths are generally unrelated to Black Lives Matter coverage. Indeed, although we do not assume that policecaused deaths of Black men and women would necessarily lead to coverage of the Black Lives Matter movement, one might expect that increases in the number of deaths would lead to an increase in coverage because protests occur in response to some deaths and, more importantly, reporters could connect police-Black violence to the broader issues discussed by Black Lives Matter. Here, we conduct our analysis at the national level to examine the success and current state of the movement, although again, given historical racialist biases, we do not expect the occurrence of Black deaths to generate increased interest in the movement.

\section{Methods}

To examine news coverage and public interest in the Black Lives Matter movement, we took a descriptive and exploratory approach to examining data from three sources: (1) newspaper mentions of the Black Lives Matter movement from LexisNexis Academic, (2) crowdsourced data on police-caused deaths of Black persons in the United States, and (3) Google Trends data on Black Lives Matter searches. Data cover the time period from May 2013 to November 2016. Our initial primary goals were twofold: (1) to examine aggregate coverage of the Black Lives Matter movement by traditional news media and (2) to determine by means of basic statistics and visualization techniques if media mentions of the Black Lives Matter movement correlate with police-caused deaths of Black individuals. 
This research has contributed to our understanding of police use of force against Black citizens by documenting the extent to which police-caused deaths of Black men and women do or do not generate interest in Black Lives Matter, an organization that directly confronts the issue of racially biased policing. Our general methodological strategy was descriptive and exploratory. Specifically, we followed the advice of Maltz $(1998,2006)$ to allow the data to generate hypotheses. As detailed below, we noted a spike in Black Lives Matter coverage in July 2016, which we believe was linked to the killing of five police officers at a Black Lives Matter protest in Dallas, Texas. Therefore, although it was not our original intent to do so, we also examined July 2016 from the perspective of an interrupted time series - that is, we attempted to describe the extent to which coverage and interest in Black Lives Matter changed following this month. This analysis served as a tool to examine the degree to which police deaths appeared to matter more than the deaths of Black men and women. To do this, we used interrupted time series analysis because this quasiexperimental method is well suited for detecting instantaneous and long-term changes in an outcome variable (news mentions of Black Lives Matter). As a robustness check, we made use of Google Trends data to ensure that our news mention data were accurately capturing trends in the public interest and coverage of the Black Lives Matter movement

\section{Black Lives Matter News Mentions}

Using the LexisNexis Academic search feature, we searched the term "Black Lives Matter," expanding the search to include "blacklivesmatter" and "\#blacklivesmatter" as well, to account for phrasings that were formatted differently. In addition, we searched for both "BLM" and "\#BLM", although we included the "\#BLM" results only in our monthly counts of news mentions because the search "BLM" also returned results related to the Bureau of Land Management. Specifically, each month from July 2013 to December 2016 was searched for newspaper articles containing one or more of the above terms, and this search was completed for five regions (Midwest, Northeast, Southeast, Southwest, and Northwest). The LexisNexis output was a list of articles with a headline containing the search term. For each search, the title and preview panel for the articles were reviewed to ensure that they were about the correct topic, and a count per region-month was created. Mentions were manually counted and verified by the "results" feature, which listed the number of articles containing the keywords within the headline. Although these data were eventually aggregated to the entire nation and combined in a single data set, this monthby-month and region-by-region process was important for ensuring that LexisNexis Academic would produce all relevant articles (non-disaggregated searches would cap out with a maximum number of articles).

\section{Police-Caused Deaths}

Although much of the research on race and police violence has made use of the FBI Supplementary Homicide Reports (Jacobs, 1998; Willits \& Nowacki, 2014), research suggests that these data miss many lethal force incidents (Barber et al., 2016). For this reason, a number of efforts to collect alternative measures of police violence have started since 2013. For this project, we obtained our data from "mappingpoliceviolence.com," which aggregates data from several crowdsourced efforts. Early work comparing crowdsourced data versus a subset of data requested with the Freedom of Information Act 
indicate that crowdsourced data on police violence are highly accurate (Farman, 2015), and a number of studies using crowdsourced data have been published (Campbell, Nix, \& Maguire, 2017; Hirschfield, 2015; Ross, 2015; Ross, Winterhalder, \& McElreath, 2018).

\section{Google Trends Data}

Although our analysis focused first on examining the degree to which traditional news media cover the Black Lives Matter movement and the extent to which coverage is associated with police-caused deaths of Black men and women, we also used Google Trends data to examine the popularity of Google searches for Black Lives Matter during the same time period. We included Internet search data as a robustness check to ensure that the LexisNexis news data accurately captured trends in how often the public is discussing Black Lives Matter (ie, we would expect searches for Black Lives Matter to increase during months with more news coverage). Google Trends provides a normalized rating (from 0 to 100) of the popularity of a particular search term over a specified period. These data do not reflect the frequency or total number of searches, but rather the relative popularity of a particular search term. Researchers suggest that Google Trends data are a useful measure of public attention to a given topic (Ripberger, 2011), and a small body of criminological research makes use of these data (Makin \& Morczek, 2015, 2016; Song, Song, An, Hayman, \& Woo, 2014)

\section{Results}

We begin by examining the link between news mentions and the deaths of Black persons descriptively, with a focus on the visual examination of trends. Here, we follow the advice of Maltz $(1998,2006)$ to use visualization not only for description but also as an integral tool for generating hypotheses. In this case, we first examine the visual trends in news mentions and then inductively generate hypotheses to explain these trends.

Figure 1: Black Lives Matter Newspaper Mentions and Police-Caused Deaths of Blacks

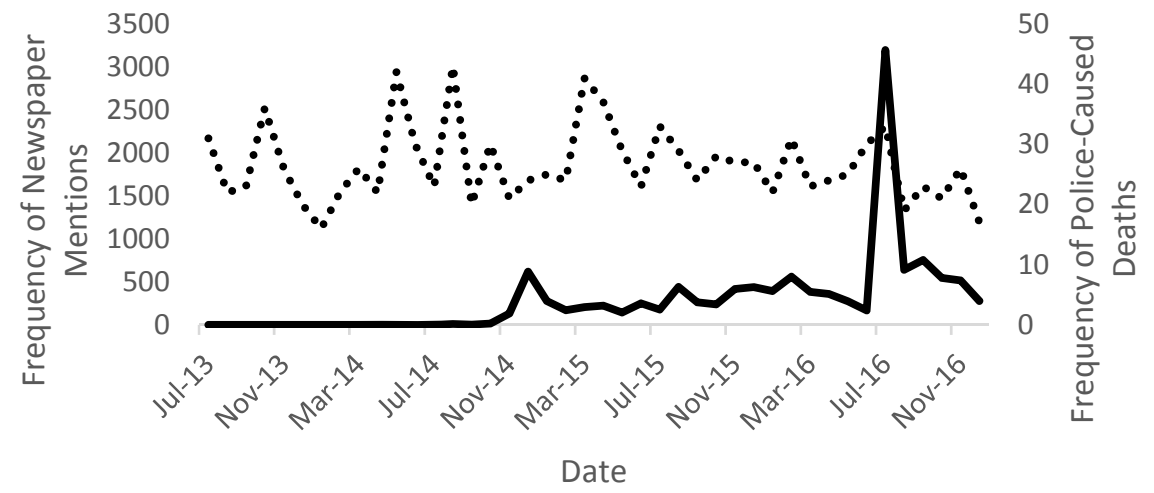


Black Lives Matter did not pick up any significant traction in news coverage in any part of the country until late 2014, despite the fact that the term "Black Lives Matter" was coined in July of 2013. The absence of high-profile police-caused deaths of Black men or women during this period and the general decline in the number of police-caused deaths of Blacks from the summer peaks of 2014 suggest some other impetus for early coverage of the movement. The most likely explanation is the increased news coverage following the Ferguson protests and riots following the acquittal of a police officer charged with killing Michael Brown.

After this, the rate of news mentions declines and is relatively steady until July of 2016, at which point the coverage of Black Lives Matter increases substantially and dramatically. A total of 3,115 articles during July 2016 contained the phrase "Black Lives Matter," although importantly, the numbers declined immediately in subsequent months. A number of people of color were killed by police around this time, but the number of Black persons killed by police was not dramatically greater than in prior months. Figure 1 presents a time series chart of the number of Black individuals killed by police officers (dotted line) and the number of newspaper mentions of Black Lives Matter (solid line) over the same period. Although the number of deaths does show some variation from month to month, no substantial variation is seen that would explain why news mentions of the Black Lives Matter movement increased so dramatically in July 2016. Interestingly, this pattern was consistent across the country. Using newspaper mention data disaggregated by region, we observed a similar pattern across the country (with slightly more mentions of Black Lives Matter in newspapers located in the Midwest and Southeast areas of the United States).

After a quick review of some of the news articles that emerged in July 2016, it became clear that the July 2016 increase was related to an incident that occurred at a Black Lives Matter protest in Dallas, Texas. On July 7, 2016, Micah Xavier Johnson ambushed officers during a Black Lives Matter protest, killing five police officers and wounding seven more, as well as two civilians (NBC 5, 2016). The protest was against the shootings of Alton Sterling and Philando Castile, who had been killed by police in separate incidents just days before. Johnson made national news, not only as the first person to be killed in America by a police robot (Selyukh \& Rosenberg, 2016) but also, more predominantly, as a radical Black Lives Matter militant responsible for the deadliest incident in terms of police deaths since the September 11, 2001, terror attacks. The shooting gave validity to negative perceptions of the movement, potentially contributing to the increased number of articles in July 2016.

Although the dramatic increase in news mentions in July 2016 is visually apparent, we also present the results of a simple, single-group interrupted time series model to demonstrate that this change in the number of news mentions of Black Lives Matter was a statistically significant departure from the amount of prior news coverage. Several different approaches can be used to examine the effect of a specific interruption on a given trend, but the interrupted time series model is widely accepted as one of the strongest quasiexperimental approaches for identifying the short- and long-term effects of interventions (Bernal, Cummins, \& Gasparrini, 2017; Cook, Campbell, \& Day, 1979; Wagner, Soumerai, Zhang, \& Ross-Degnan, 2002) and has been used in the criminological literature (Chamlin, 2017; Koslicki, 2017; Vásquez, Maddan, \& Walker, 2008). Here, we make use of the 
segmented regression approach to interrupted time series modeling described by Linden (2015), which uses the following formula:

$$
Y_{t}=\beta_{0}+\beta_{1} T_{t}+\beta_{2} X_{t}+B_{3} X_{t} T_{t}
$$

where $Y_{t}$ is the outcome measure at time $t, T_{t}$ is the time since the study start, and $X_{t}$ is a dummy variable indicating whether some interruption has happened $\left(X_{t}=1\right)$ or not $\left(X_{t}=\right.$ $0)$. In terms of interpretation, this model is formulated such that $\beta_{1}$ is the trend in the outcome variable before the interruption point, $\beta_{2}$ is the immediate effect of the interruption, and $B_{3}$ is the trend in the outcome variable following the interruption point. In addition to displaying the trend in an outcome variable directly, this model makes use of Newey-West standard errors to account for autocorrelation. To simplify the analysis, we explored an interrupted time series for all of the Black Lives Matter mentions (not disaggregated by month). Therefore, for this study, $Y_{t}$ is the number of news mentions for Black Lives Matter in a given month, $T_{t}$ is the number of months since July 2013, and $X_{t}$ is a dummy variable for July 2016 and onward (as we are conceptualizing the Dallas shooting as the interruption point). The results of this model are presented in Table 1.

TABLE 1: Interrupted Time Series Analysis of Black Lives Matter Newspaper Mentions

\begin{tabular}{lc}
\hline & Newspaper Mentions (SE) \\
\hline Time & $15.98^{* *}(1.75)$ \\
Intervention Point 1: July 2016 & $1354.67^{ \pm *}(636.55)$ \\
Time x Intervention Point 1 & $-259.19^{*}(127.87)$ \\
Constant & $-104.39^{* *}(30.32)$ \\
$\mathrm{F}_{5,54}$ & $33.77^{* *}$ \\
\hline
\end{tabular}

NOTE: Regression coefficients with Newey-West standard errors (SE) in parentheses.

${ }^{*} p<.05 ;{ }^{* *} p<.01$

These results confirm that Black Lives Matter newspaper mentions increased dramatically at the point of intervention (July 2016). Specifically, an immediate increase of more than 1,350 news mentions occurred during July 2016. The model also demonstrates that news mentions declined significantly following this month, suggesting that the news focus on Black Lives Matter was short-lived and not reflective of a change in the volume of news coverage for the movement.

As a robustness check, we also used the previously described Google Trends data to examine trends in Internet searches for Black Lives Matter. Given that our initial analysis of the news mention data had generated the hypothesis that the increased coverage was in response to the July 2016 shooting deaths of five police officers, we expanded our search criteria to include "Blue Lives Matter" as well. Figure 2 displays Google Trend results for Black Lives Matter and Blue Lives Matter from July 2013 to December 2016.

The Google Trends data reveal the same basic pattern as the news mentions data. General interest in both Black Lives Matter and Blue Lives Matter is limited for much of the time series, with a large spike in July 2016, after which interest falls off. Interestingly, Google 
Trends data are also available by week, and although these results are smoothed by monthly averages, Black Lives Matter received a Google Trend score of 100 during the second week of July 2016, indicating that it was among the most searched-for terms on the Internet in the United States (searches for Blue Lives Matter peaked during the week of the shooting, at a high Google Trends value of 40 ).

Figure 2: Google Trends on Black Lives Matter and Blue Lives Matter Internet Searches

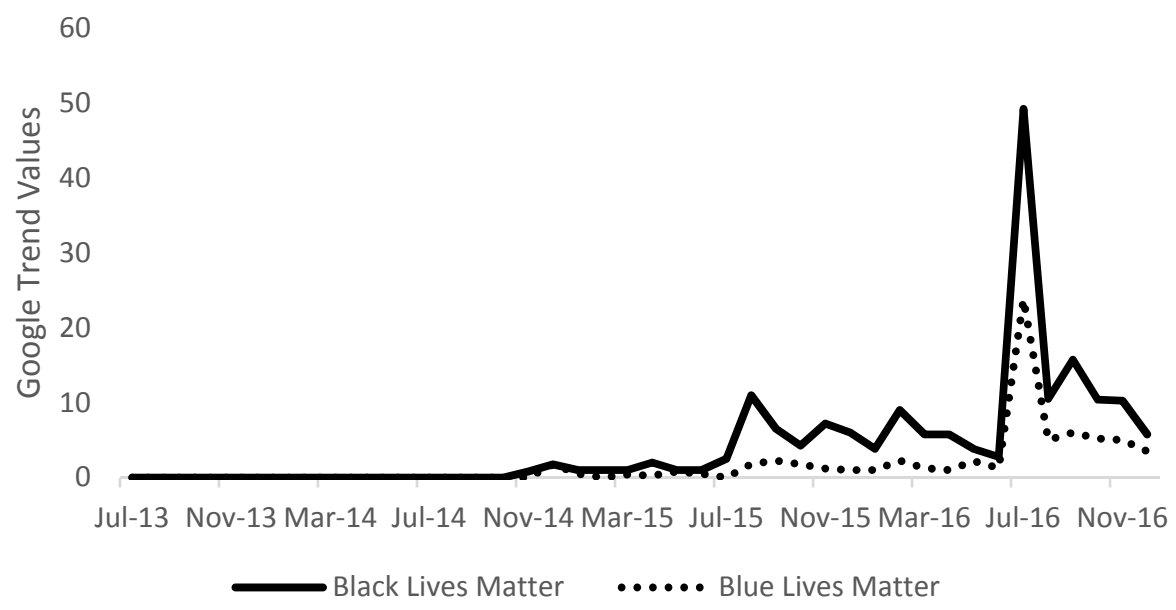

Taken together, these data suggest that neither Black Lives Matter news mentions nor Internet searches for Black Lives Matter are related to police-caused deaths of Black individuals. Although the visual trends presented seem clear, we also examined bivariate correlations between police-caused deaths of Black men and women and Google Trends results for Black Lives Matter, and between police-caused deaths and newspaper mentions of Black Lives Matter. The results, presented in Table 2, support the conclusion that an increased number of deaths does not result in additional news coverage or Internet searches for Black Lives Matter. They do provide a robustness check for our measure of newspaper mentions as our monthly newspaper mention values correlate strongly and significantly with the Google Trends measure. Importantly, no significant correlation was found between police-caused deaths of Black individuals and news mentions or between police-caused deaths and Google searches.

TABLE 2: Pearson Correlations Between Police-Caused Black Deaths and Black Lives Matter Newspaper Mentions and Between Deaths and Internet Searches

\begin{tabular}{lccc}
\hline & Black Deaths & Newspaper Mentions & Google Trends \\
\hline Black Deaths & - & - & - \\
Newspaper Mentions & .032 & - & - \\
Google Trends & -.018 & $.822^{* *}$ & - \\
\hline
\end{tabular}

${ }^{*} p<.05 ;{ }^{* *} p<.01$ 


\section{Discussion}

Analyzing trends in newspaper mentions of and Internet searches for Black Lives Matter and examining the relationship between these trends and police-caused deaths of Black men and women suggest that the mainstream news media and the average person searching the Internet are not particularly interested in Black Lives Matter. Moreover, no evidence suggests that interest in Black Lives Matter increased over time as more Black individuals were killed or that interest in Black Lives Matter corresponded in a meaningful way with police-caused deaths of Black persons. Put simply, no great outpouring of news articles has addressed the movement or the need for the movement following the death of a Black person at the hands of police, nor is the public at large searching out Black Lives Matter in response to these actions. The only significant shift in coverage and Internet interest in Black Lives Matter happened after the tragic death of five police officers in Dallas at a Black Lives Matter protest. A cynical interpretation is that our results indicate that Blue Lives Matter more.

In some sense, these results are unsurprising. First, police deaths are tragic and can involve a great deal of public outcry and attention. For example, Pantti and Sumiala (2009) note that certain police deaths can produce a sense of national tragedy and instigate public mourning rituals, although interestingly, other research suggests that most police deaths go unnoticed by the public (Kynoch, 2003). Importantly, research also demonstrates that particularly tragic deaths can result in dramatic shifts in news coverage. For example, Rosie and Gorringe (2009) argue that newspaper media largely ignored police actions against protesters before the police-caused death of an innocent bystander at the 2009 G20 summit protests, and that this death was enough to cause a shift in how the media cover these protests. More broadly, substantial evidence indicates that media coverage tends to focus on sensational and violent themes, especially with regard to the coverage of social movements and related protests (Donson, Chesters, \& Welsh, 2004; Juris, 2005).

Further, the fact that the only spike in news coverage of and Internet searches for the movement occurred following a negative event supports much of what we know regarding racialized patterns of news coverage. Regarding the Black Lives Matter movement specifically, Leopold and Bell (2017) have previously shown that much of the mainstream coverage of the movement is negative, and research on the Civil Rights Movement demonstrated that media coverage became more and more negative over time (Bond, 2001). We consider these findings to be supportive of the argument of Van Dijk (2015) that the routinized structure of modern news places an emphasis on stories that are attentiongrabbing, fast to produce, and sensational, and that this process ultimately reproduces systemic racial bias.

The current results are supportive of these trends. Put simply, police-caused deaths of Black citizens and the resultant social movement responses may not be sensationalist enough to attract sustained media attention, whereas the deaths of five police officers fit the "if it bleeds, it leads" approach to media coverage. Of course, we do not mean to diminish the deaths of these police officers or to suggest that this incident should not have generated considerable news coverage and Internet searching. Our interpretation of our results is simply that the deaths of hundreds of Black citizens at the hands of police in the years covered by our data did not result in any appreciable increase in news coverage of or Internet searches for the Black Lives Matter movement, whereas the tragic deaths of 
the police officers in Dallas did. As policing in Black communities is one of the major areas of emphasis for Black Lives Matter, the lack of general coverage of Black Lives Matter and the concurrent and heightened specific coverage of police deaths associated with a Black Lives Matter protest might have the effect of reproducing systemic biases by further devaluing the lives of Black people through both neglect and stereotyping.

In addition to the previously described studies showing that Black individuals and communities are differentially policed, broad research has examined the stereotype of the dangerous Black criminal (Dixon \& Maddox, 2005; Dixon \& Rosenbaum, 2004; Johnson \& King, 2017), and an entire body of research suggests that being the member of a racial minority, and in particular being Black, is a focal concern that affects the degree to which a person is viewed as blameworthy (Crow \& Adrion, 2011; Nowacki, 2015; Steffensmeier, Ulmer, \& Kramer, 1998). Indeed, many theorists have commented on the manner in which race, ethnicity, and other ascribed characteristics can affect how people are perceived and treated by the criminal justice system. Black individuals, as well as members of other minorities, have been considered classified as the dangerous underclass (Wilson, 2012), the symbolic assailant (Skolnick, 1966), or the suitable enemy (Wacquant, 1999). In this regard, the lack of news coverage and Internet searches in response to Black deaths may simply be part of a broader pattern of discrimination and racism against Black individuals and Black communities.

Nonetheless, our results are indicative of an interesting juxtaposition. The Black Lives Matter movement was successful in helping to generate some level of criminal justice policy reform, such as legislative changes outlined by Campaign Zero, in at least 10 states (WeTheProtesters, 2018), yet the movement has not been successful in garnering ongoing news attention or in attracting broad interest from the American public. The apparent paradox between how Black Lives Matter is able to produce changes on the ground while not receiving broad coverage from the news media or generating substantial Internet searches is an interesting and important quandary. If more people are not actively discussing why Black lives matter, is the movement successful?

Of course, it is impossible to discuss the success of the Black Lives Matter movement without remembering that it started as an online movement. It is entirely possible that the social movement is fueled by instances of police violence, and that although traditional media coverage is not reflective of this pattern, noticeable increases in online mentions and hashtag use have occurred. Research suggests that Twitter has been the predominant hub for Black Lives Matter information (Freelon et al., 2016). Social movements with a strong online presence have a number of advantages (Mundt, Ross, \& Burnett, 2018). For example, whereas traditional social movements often either focused on local residents or required people to travel great distances to participate, online-oriented social movements can frequently involve activists from around the world in both in-person and online activities (Hara \& Huang, 2011). In this regard, it may be the case that Black Lives Matter is targeting individuals on Twitter and is quite successful at energizing and mobilizing its base. Indeed, the population that consumes traditional news media may not be broadly reflective of the Black Lives Matter message.

For example, the Pew Research Center found that the largest percentage of consumers of traditional news (network television and print newspapers) consisted of persons aged 50 and older, whereas the largest percentage of consumers of online news 
consisted of those between the ages of 18 and 29 (Mitchell, 2016). These trends are similar to those regarding support for Black Lives Matter; only 37\% of adults aged 50 to 64 expressed support for the movement, and those aged 65 and older showed even less support, at $26 \%$, whereas $60 \%$ of those younger than 30 expressed support for the movement (Horowitz, 2016). Although it would be easy to conclude that the Black Lives Matter movement is unsuccessful in that it has failed to generate news coverage in response to police-caused Black deaths, it may be that in some general sense the audience that obtains information from newspapers and, indeed, from Internet searches is not the audience that the movement is trying to reach. It is, however, more difficult to explain the lack of interest as measured by Google searches. Regardless, it is difficult to envision how the Black Lives Matter movement can be more broadly successful if it is unable to reach non-core audiences. If our results suggest that both the Black Lives Matter movement and the police-caused deaths of Black men and women are not significantly capturing the public's attention, then clearly more work needs to be done.

Interestingly, some research suggests that the Black Lives Matter movement may have an indirect effect on news coverage of police-caused Black deaths (Freelon, Mcllwain, \& Clark, 2018). This does not directly contradict our results and, in fact, suggests that Black Lives Matter may lead to news coverage of such deaths without resulting in increased coverage of the movement itself. Freelon et al. purchased a data set of all public tweets from June 1, 2014, to May 31, 2015, and analyzed the public Twitter conversations started by the Black Lives Matter movement. They found that these conversations on police brutality and specific use of force incidents led to posts about similar topics by mainstream news organizations on Twitter. These results might suggest that \#Black Lives Matter attention to a given incident increases media coverage of that incident, but that the media do so in a manner that strips Black Lives Matter from the conversation (as suggested by our results and data). Freelon et al. (2018) suggest that Black Lives Matter may have an indirect effect on news coverage, whereas our research only provides evidence against a direct effect.

In addition to being unable to account for a potential indirect effect of Black Lives Matter on news coverage and public attention, our research has several other limitations. First, although the interrupted time series method is a strong tool for estimating causal effects, our formal approach is a single-group time series study. These approaches have been critiqued in the literature for not being able to isolate causal effects (Linden, 2017). In our case, we cannot definitely identify that the Dallas police shootings were the cause of the spike in media coverage and public interest in July 2016, although informally, it is clearly the case that the Dallas shooting was the primary topic of many of the newspaper articles including the phrase "Black Lives Matter." It is beyond the scope of this research to explain precisely whether the increased coverage was solely a matter of public and media interest or whether outside factors influenced how the incident was covered. The incident occurred during the 2016 presidential race, and (then) presidential candidate Donald Trump made significant mention of the killing of police officers. Moreover, other incidents, including the Colin Kaepernick U.S. national anthem protest, likely generated some of the media and public interest in the movement. Unfortunately, with no clear control group available, it was not possible to parse out the potential effect of these external factors. Although the potential 
for external effects is worth considering, this does little to change the conclusion that coverage and interest in Black Lives Matter are not driven by the deaths of Black persons.

Lastly, our analysis of media coverage and public interest is narrow in that it focuses on newspaper mentions and Internet searches. Given historical trends in how the media cover racialized stories, it is possible that some stories did in fact cover Black Lives Matter events but failed to use the movement's name or associated hashtag (and instead made use of terms like "rioters" and "looters"). Although we cannot test this possibility directly, such a result would largely coincide with the work of Leopold and Bell (2017) documenting that when Black Lives Matter is discussed following a death, it is discussed in a negative context. It is also possible that other metrics, like televised news stories, might reveal different trends. Further, as previously mentioned, much of the focus of Black Lives Matter has been on the "hashtag" social media companies (Twitter, Instagram, and Tumblr), and these data are not publicly available for analysis. Therefore, we cannot determine the degree to which the movement itself responds to and is energized by Black deaths. Moreover, although we disaggregated the data by region and found a similar pattern of media coverage, it is possible that police-caused Black deaths may have more of an effect on media coverage and Internet searches in smaller, more localized units of analysis.

Still, we believe it was important to document that police-caused deaths of Black men and women were largely unrelated to how the movement was covered. Future work should explore the degree to which the national and regional patterns we have revealed persist at the county or city level, and especially the role that the race of a population plays in coverage of the movement. Lastly, we are unable to describe the manner in which the news media covered Black Lives Matter (either in general or following the Dallas incident). Although Leopold and Bell (2017) have demonstrated that media coverage of Black Lives Matter is generally negative, important questions still remain regarding whether different types of newspapers cover the movement differently and to what extent the Dallas incident shifted how coverage occurred. This latter question is especially important as historically, a shift in media focus on protesters and their legitimate demands to a focus on "violent looters" and "kooks" has been the point at which the social movement's cause ceases to be a story (Bond, 2001).

\section{Conclusions}

Our primary goal was to examine the degree to which news coverage of the Black Lives Matter movement was associated with police-caused deaths of Black individuals. As a robustness check, we also examined the degree to which Internet searches were associated with police-caused deaths of Black individuals in the United States. Interestingly, although newspaper mentions and Google searches of Black Lives Matter were strongly related, neither was related to police-caused deaths of Black men and women. Our results plainly suggest that public and news interest in Black Lives Matter is not affected by the number of police-caused deaths of Black individuals. Conversely, the tragic death of five police officers at a Black Lives Matter protest appeared to result in a large and statistically significant increase in news mentions and searches. These results suggest that Blue Lives appear to matter more than Black Lives, at least in terms of news coverage and Internet searches. 
It is important to put these results in context within the broader literature on race and use of force. Although our work does not address differential rates of police use of force, the lack of public interest in the topic is interesting in that it seems to reflect an ongoing debate within academia. A number of studies have produced laboratory results suggesting that officers are in fact slower to use force against minority suspects (James, James, \& Vila, 2016; James Klinger, \& Vila, 2014; James, Vila, \& Daratha, 2013), and researchers have suggested as a result that police may be "reverse racists" against White suspects. Other research has produced similar results, suggesting that early use of force is not disproportionately applied to Black suspects (Fryer, 2016; Wheeler, Phillips, Worrall, \& Bishopp, 2017). This point remains a matter of debate, as other studies have found opposite results (Correll et al., 2007; Ross, 2015; Sadler, Correll, Park, \& Judd, 2012; Willits \& Makin, 2018), and the concept of "reverse racism" has been strongly called into question (Roussell et al., 2017). The debate continues, though. Ross et al. (2018) argue that much of the confusion is the result of researchers using an incident as the level of analysis, whereas aggregated levels of use of force consistently demonstrate racial disparities. In any event, our results suggest that to some extent the general public and news media are not particularly concerned with this topic, yet we know that Black Lives Matter supporters are clearly concerned. Although the comparison is admittedly imperfect, we consider the academic debate regarding the extent to which racialized police use of force and the divide among the public about the same topic to be of the utmost importance, and perhaps related to the growing trend of American polarization on political topics, including issues related to policing and race (Donovan \& Klahm, 2018). More work needs to be done to better understand the academic divide both on racialized patterns of use force and on public and news interest in these and related topics.

More narrowly, and perhaps somewhat pessimistically, our results might be taken as evidence that the Black Lives Matter movement has been unsuccessful. The broader population of the United States does not in fact seem to be concerned with police-caused deaths of Black people. We caution against this interpretation, given that Black Lives Matter is ultimately a movement in its early stages and its primary focus still seems to be on online organization, which may in turn have an indirect effect on increasing the coverage of incidents of police brutality (Freelon et al., 2018). We and other scholars (Byrd et al., 2017; Cox, 2017; Leopold \& Bell, 2017; Mundt, Ross, \& Burnett, 2018) have approached Black Lives Matter as a social movement, but the disparate and loosely knit nature of the organization may classify it as a different type of movement altogether, and perhaps one that requires different measures of success. Still, our research suggests that more work needs to be done and that, at the current date, Black lives do not matter enough.

\section{Declaration of Conflicting Interests}

The author declares no potential conflicts of interest with respect to the research, authorship, and/or publication of this article.

\section{Funding}

The author received no financial support with respect to the research, authorship, and/or publication of this article. 
Journal of Criminal Justice and Law:

\section{References}

Andrews, K. T. (1997). The impacts of social movements on the political process: The civil rights movement and black electoral politics in Mississippi. American Sociological Review, 62(5), 800-819.

Andrews, K. T., \& Biggs, M. (2006). The dynamics of protest diffusion: Movement organizations, social networks, and news media in the 1960 sit-ins. American Sociological Review, 71(5), 752-777.

Barber, C., Azrael, D., Cohen, A., Miller, M., Thymes, D., Wang, D. E., \& Hemenway, D. (2016). Homicides by police: Comparing counts from the national violent death reporting system, vital statistics, and supplementary homicide reports. American Journal of Public Health, 106(5), 922-927.

Beckett, K., Nyrop, K., \& Pfingst, L. (2006). Race, drugs, and policing: Understanding disparities in drug delivery arrests. Criminology, 44(1), 105-137.

Bernal, J. L., Cummins, S., \& Gasparrini, A. (2017). Interrupted time series regression for the evaluation of public health interventions: A tutorial. International Journal of Epidemiology, 46(1), 348-355.

BlackLivesMatter. (2017). Black lives matter. Herstory.

Bond, J. (2001). The media and the movement: Looking back from the southern front. In B. Ward (Ed.), Media, culture, and the modern African American freedom struggle (pp. 16-40). Gainesville, FL: University Press of Florida.

Buchanan, L., Fessenden, F., Lai, R. K. K., Park, H., Parlapiano, A., Tse, A., ... Yourish, K. (2015, August 10). What happened in Ferguson? The New York Times.

Byrd, W. C., Gilbert, K. L., \& Richardson Jr., J. B. (2017). The vitality of social media for establishing a research agenda on black lives and the movement. Ethnic and Racial Studies, 40(11), 1872-1881.

Campbell, B. A., Nix, J., \& Maguire, E. R. (2017). Is the number of citizens fatally shot by police increasing in the post-Ferguson era? Crime \& Delinquency.

Cesario, J., Johnson, D., \& Terrill, W. (2018). Is there evidence of racial disparity in police use of deadly force? Analyses of officer-involved fatal shootings in 2015-2016. Social Psychological and Personality Science.

Chamlin, M. B. (2017). An interrupted time series analysis of the differential impact of New Jersey's BAC legislation on driver and passenger crash fatalities. Journal of Crime and Justice, 40(4), 542-549.

Chiricos, T., \& Eschholz, S. (2002). The racial and ethnic typification of crime and the criminal typification of race and ethnicity in local television news. Journal of Research in Crime and Delinquency, 39(4), 400-420.

Cook, T. D., Campbell, D. T., \& Day, A. (1979). Quasi-experimentation: Design \& analysis issues for field settings (Vol. 351). Boston, MA: Houghton Mifflin.

Correll, J., Park, B., Judd, C. M., Wittenbrink, B., Sadler, M. S., \& Keesee, T. (2007). Across the thin blue line: Police officers and racial bias in the decision to shoot. Journal of Personality and Social Psychology, 92(6), 1006.

Cox, J. M. (2017). The source of a movement: Making the case for social media as an informational source using Black Lives Matter. Ethnic and Racial Studies, 40(11), 1847-1854. 
Crow, M. S., \& Adrion, B. (2011). Focal concerns and police use of force: Examining the factors associated with Taser use. Police Quarterly, 14(4), 366-387.

Cullors, P. (2017). Organizations: Black Lives Matter.

Davis, L. R., \& Harris, O. (2002). Race and ethnicity in US sports media. In L Wenner (Ed.), MediaSport (pp. 168-170). London, UK: Routledge.

Diani, M. (1992). The concept of social movement. The Sociological Review, 40(1), 1-25.

Dixon, T. L., \& Maddox, K. B. (2005). Skin tone, crime news, and social reality judgments: Priming the stereotype of the dark and dangerous black criminal. Journal of Applied Social Psychology, 35(8), 1555-1570.

Dixon, J. C., \& Rosenbaum, M. S. (2004). Nice to know you? Testing contact, cultural, and group threat theories of anti-Black and anti-Hispanic stereotypes. Social Science Quarterly, 85(2), 257-280.

Donovan, K. M., \& Klahm IV, C. F. (2018). How priming innocence influences public opinion on police misconduct and false convictions: A research note. Criminal Justice Review, 43(2), 174-185.

Donson, F., Chesters, G., \& Welsh, I. (2004). Rebels with a cause, folk devils without a panic: Press jingoism, policing tactics and anti-capitalist protests in London and Prague. Internet Journal of Criminology.

Farman, L. E. (2015). Validation of volunteered geographic information quality components for incidents of law enforcement use of force (Doctoral dissertation). University of Southern California, Los Angeles, CA.

Freelon, D., Mcllwain, C., \& Clark, M. (2016). Beyond the hashtags: \#Ferguson, \#Blacklivesmatter, and the online struggle for offline justice. Washington, DC: American University, Center for Media \& Social Impact.

Freelon, D., Mcllwain C., \& Clark, M. (2018). Quantifying the power and consequences of social media protest. New Media \& Society, 20(3), 990-1011.

French, D. (2016, July 11). Black lives matter: Radicals using moderates to help tear America apart. National Review.

Fryer Jr., R. G. (2016). An empirical analysis of racial differences in police use of force (No. w22399). National Bureau of Economic Research.

Gelman, A., Fagan, J., \& Kiss, A. (2007). An analysis of the New York City police department's "stop-and-frisk" policy in the context of claims of racial bias. Journal of the American Statistical Association, 102(479), 813-823.

Greenwald, A. G., Poehlman, T. A., Uhlmann, E. L., \& Banaji, M. R. (2009). Understanding and using the Implicit Association Test: III. Meta-analysis of predictive validity. Journal of Personality and Social Psychology, 97(1), 17.

Hall, J. D. (2005). The long civil rights movement and the political uses of the past. The Journal of American History, 91(4), 1233-1263.

Hara, N., \& Huang, B. Y. (2011). Online social movements. Annual Review of Information Science and Technology, 45(1), 489-522.

Hawkins, D. F. (2002). Devalued lives and racial stereotypes. In S. L. Gabbidon, H. T. Green, \& V. D. Young (Eds.), African American classics in criminology and criminal justice (pp. 199-212). Thousand Oaks, CA: Sage Publications.

Hirschfield, P. J. (2015). Lethal policing: Making sense of American exceptionalism. Sociological Forum, 30(4), 1109-1117. 
Journal of Criminal Justice and Law:

Horowitz, J., \& Livingston, G. (2016, July 8). How Americans view the Black Lives Matter movement. Pew Research Center.

Huizinga, D. H., Thornberry, T., Knight, K., Lovegrove, P., Loeber, R., Hill, K., \& Farrington, D. P. (2007). Disproportionate minority contact in the juvenile justice system: A study of differential minority arrest/referral to court in three cities. Washington, DC: Office of Juvenile Justice and Delinquency Prevention.

Ince, J., Rojas, F., \& Davis, C. A. (2017). The social media response to Black Lives Matter: How Twitter users interact with Black Lives Matter through hashtag use. Ethnic and Racial Studies, 40(11), 1814-1830.

Jacobs, D. (1998). The determinants of deadly force: A structural analysis of police violence. American Journal of Sociology, 103(4), 837-862.

James, L., James, S. M., \& Vila, B. J. (2016). The reverse racism effect: Are cops more hesitant to shoot black than white suspects? Criminology \& Public Policy, 15(2), 1-23.

James, L., Klinger, D., \& Vila, B. (2014). Racial and ethnic bias in decisions to shoot seen through a stronger lens: Experimental results from high-fidelity laboratory simulations. Journal of Experimental Criminology, 10(3), 323-340.

James, L., Vila, B., \& Daratha, K. (2013). Results from experimental trials testing participant responses to White, Hispanic and Black suspects in high-fidelity deadly force judgment and decision-making simulations. Journal of Experimental Criminology, 9(2), 189-212.

Johnson, B. D., \& King, R. D. (2017). Facial profiling: Race, physical appearance, and punishment. Criminology, 55(3), 520-547.

Juris, J. S. (2005). Violence performed and imagined: Militant action, the Black Bloc and the mass media in Genoa. Critique of Anthropology, 25(4), 413-432.

Kamel, S. H. (2014). Egypt's ongoing uprising and the role of social media: Is there development?. Information Technology for Development, 20(1), 78-91.

Kavada, A. (2015). Creating the collective: Social media, the Occupy Movement and its constitution as a collective actor. Information, Communication \& Society, 18(8), 872886.

Koslicki, W. (2017). SWAT mobilization trends: Testing assumptions of police militarization. Policing: An International Journal of Police Strategies \& Management, 40(4), 733-747.

Kynoch, G. (2003). Friend or foe? A world view of community-police relations in Gauteng Townships, 1947-77. Canadian Journal of African Studies/La Revue canadienne des études africaines, 37(2-3), 298-327.

Leopold, J., \& Bell, M. P. (2017). News media and the racialization of protest: an analysis of Black Lives Matter articles. Equality, Diversity and Inclusion: An International Journal, 36(8), 720-735.

Linden, A. (2015). Conducting interrupted time-series analysis for single- and multiplegroup comparisons. Stata Journal, 15(2), 480-500.

Linden, A. (2017). Challenges to validity in single-group interrupted time series analysis. Journal of Evaluation in Clinical Practice, 23(2), 413-418.

Lundman, R. J., \& Kaufman, R. L. (2003). Driving while black: Effects of race, ethnicity, and gender on citizen self-reports of traffic stops and police actions. Criminology, 41(1), 195-220.

Makin, D. A., \& Morczek, A. L. (2015). The dark side of internet searches: A macro level assessment of rape culture. International Journal of Cyber Criminology, 9(1), 1-23. 
Makin, D. A., \& Morczek, A. L. (2016). X views and counting: Interest in rape-oriented pornography as gendered microaggression. Journal of Interpersonal Violence, 31(12), 2131-2155.

Maltz, M. D. (1998). Visualizing homicide: A research note. Journal of Quantitative Criminology, 14(4), 397-410.

Maltz, M. D. (2006). Some $p$-baked thoughts $(p>0.5)$ on experiments and statistical significance. Journal of Experimental Criminology, 2(2), 211-226.

Mitchell, A., Gottfried, J., Barthel, M., \& Shearer, E. (2016, July 07). The modern news consumer: News attitudes and practices in the digital era. Pew Research Center.

Mundt, M., Ross, K., \& Burnett, C. M. (2018). Scaling social movements through social media: The case of Black Lives Matter. Social Media + Society, 4(4).

NBC 5. (2016, July 7). Sniper ambush kills 5 officers, injures 7 in Dallas following peaceful protest.

Nowacki, J. S. (2015). Race, ethnicity, and judicial discretion: The influence of the United States v. Booker decision. Crime \& Delinquency, 61(10), 1360-1385.

Oliver, M. B. (2003). African American men as "criminal and dangerous": Implications of media portrayals of crime on the "criminalization" of African American men. Journal of African American Studies, 7(2), 3-18.

Pantti, M., \& Sumiala, J. (2009). Till death do us join: Media, mourning rituals and the sacred centre of the society. Media, Culture \& Society, 31(1), 119-135.

Quillian, L., \& Pager, D. (2001). Black neighbors, higher crime? The role of racial stereotypes in evaluations of neighborhood crime. American Journal of Sociology, 107(3), 717-767.

Reynolds, B. (2015, August 24). I was a civil rights activist in the 1960s. But it's hard for me to get behind Black Lives Matter. The Washington Post.

Ripberger, J. T. (2011). Capturing curiosity: Using internet search trends to measure public attentiveness. Policy Studies Journal, 39(2), 239-259.

Rosie, M., \& Gorringe, H. (2009). What a difference a death makes: Protest, policing and the press at the G20. Sociological Research Online, 14(5), 1-12.

Ross, C. T. (2015). A multi-level Bayesian analysis of racial bias in police shootings at the county-level in the United States, 2011-2014. PLoS One, 10(11), e0141854.

Ross, C. T., Winterhalder, B., \& McElreath, R. (2018). Resolution of apparent paradoxes in the race-specific frequency of use-of-force by police. Palgrave Communications, 4(1), 61.

Roussell, A., Henne, K., Glover, K. S., \& Willits, D. (2017). Impossibility of a "reverse racism" effect: A rejoinder to James, James, and Vila. Criminology \& Public Policy.

Sadler, M. S., Correll, J., Park, B., \& Judd, C. M. (2012). The world is not black and white: Racial bias in the decision to shoot in a multiethnic context. Journal of Social Issues, 68(2), 286-313.

Sellers, R. M., \& Shelton, J. N. (2003). The role of racial identity in perceived racial discrimination. Journal of Personality and Social Psychology, 84(5), 1079.

Selyukh, A., \& Rosenberg, G. (2016, July 08). Bomb robots: What makes killing In Dallas different and what happens next? NPR.

Skolnick, J. H. (1966). Justice without trial: Law enforcement in democratic society. New York, NY: John Wiley \& Sons. 
Sommers, S. R., Apfelbaum, E. P., Dukes, K. N., Toosi, N., \& Wang, E. J. (2006). Race and media coverage of Hurricane Katrina: Analysis, implications, and future research questions. Analyses of Social Issues and Public Policy, 6(1), 39-55.

Song, T. M., Song, J., An, J. Y., Hayman, L. L., \& Woo, J. M. (2014). Psychological and social factors affecting Internet searches on suicide in Korea: A big data analysis of Google search trends. Yonsei Medical Journal, 55(1), 254-263.

Stampler, L. (2014, August 11). Twitter users ask what photo media would use \#IfTheyGunnedMeDown. Time.

Steffensmeier, D., Ulmer, J., \& Kramer, J. (1998). The interaction of race, gender, and age in criminal sentencing: The punishment cost of being young, black, and male. Criminology, 36(4), 763-798

Van Dijk, T. A. (2015). Racism and the press. London, UK: Routledge.

Vásquez, B. E., Maddan, S., \& Walker, J. T. (2008). The influence of sex offender registration and notification laws in the United States: A time-series analysis. Crime \& Delinquency, 54(2), 175-192.

Wacquant, L. (1999). 'Suitable enemies.' Foreigners and immigrants in the prisons of Europe. Punishment \& Society, 1(2), 215-222.

Wagner, A. K., Soumerai, S. B., Zhang, F., \& Ross-Degnan, D. (2002). Segmented regression analysis of interrupted time series studies in medication use research. Journal of Clinical Pharmacy and Therapeutics, 27(4), 299-309.

WeTheProtesters. (2018). We the protesters: Executive summary.

Welch, K. (2007). Black criminal stereotypes and racial profiling. Journal of Contemporary Criminal Justice, 23(3), 276-288.

Wheeler, A. P., Phillips, S. W., Worrall, J. L., \& Bishopp, S. A. (2017). What factors influence an officer's decision to shoot? The promise and limitations of using public data. Justice Research and Policy, 18(1), 48-76.

Willits, D. W., \& Makin, D.A. (2018). Show me what happened: Analyzing use of force through analysis of body-worn camera footage. Journal of Research in Crime and Delinquency, 55(1), 51-77.

Willits, D. W., \& Nowacki, J. S. (2014). Police organisation and deadly force: An examination of variation across large and small cities. Policing and Society, 24(1), 6380.

Wilson, W. J. (2012). The truly disadvantaged: The inner city, the underclass, and public policy. Chicago, IL: University of Chicago Press.

\section{Authors' Biographies}

Francesca Bordonaro graduated from Washington State University in 2017 with a bachelor's degree in criminal justice. This article is based on her honor's thesis.

Dale Willits is an assistant professor of criminal justice and criminology at Washington State University. His research interests include police-community interactions, with a particular focus on race and policing. 